\title{
Pragmatic functions of discourse marker 'well' in selected spoken discourse of Philippine English
}

\author{
Jimmylen Zuñiga-Tonio \\ Catanduanes State University - Catanduanes \\ jztonio17@gmail.com
}

DOI: http://doi.org/ 10.36892/ijlls.v3i3.665

\begin{tabular}{|c|c|}
\hline $\begin{array}{l}\text { Received: } \\
\text { 04/08/2021 }\end{array}$ & $\begin{array}{l}\text { Abstract } \\
\text { The present paper investigates the use of the discourse marker "well," one of }\end{array}$ \\
\hline $\begin{array}{l}\text { Accepted: } \\
25 / 09 / 2021\end{array}$ & $\begin{array}{l}\text { the expressions that evoke emotive rather than referential functions. Taking a } \\
\text { discourse-pragmatic approach, this study examines the functions of well as a } \\
\text { discourse marker in selected spoken discourse of Philippine English. This } \\
\text { paper investigates the functions and frequency of the discourse marker well in }\end{array}$ \\
\hline $\begin{array}{l}\text { Keywords: } \\
\text { discourse marker, ICE- } \\
\text { PH, corpus, discourse } \\
\text { analysis, pragmatic } \\
\text { functions }\end{array}$ & $\begin{array}{l}\text { various speech event categories set in a dialogue and monologue } \\
\text { environments. The data for the analysis have been selected from the } \\
\text { International Corpus of English - Philippines (ICE-PHI). Also, the study } \\
\text { focuses on the spoken component of the ICE-PH, which is one of the least } \\
\text { studied dimensions of Philippine English. Further, it employs both } \\
\text { quantitative and qualitative analyses while applying the suggested } \\
\text { classification proposed by Ran (2003) and Jucker (1993). This study claims } \\
\text { that the discourse marker well has several discourse-pragmatic functions in } \\
\text { various speaking contexts, including 1) initiating utterance; 2) indicating the } \\
\text { speaker's hesitancy; 3) mitigating various Face Threatening Acts; 4) } \\
\text { correcting one's utterance; and 5) changing or shifting the current topic, } \\
\text { based on } 346 \text { cases of well in four different spoken types. }\end{array}$ \\
\hline
\end{tabular}

\section{INTRODUCTION}

Speakers frequently employ a number of signals as tactics for implementing successful communication in communication, particularly in spoken contact. Also, second language (L2) speakers often rely on communication strategies in order to compensate for the inadequacy of their L2 resources in their L2 use. Nevertheless, discourse markers (DMs) as defined by Schiffrin (1987) are among the linguistics signals that are sequentially dependent features that bracket units of speech. Discourse markers like 'but', 'and', 'so', 'well', 'you know', 'I mean', or 'by the way' can be included among the signals that are employed to keep the discourse segments of speech in synch. DMs are linguistic expressions that are drawn from various classes rather than forming a syntactic class. Discourse markers, according to Schiffrin (1987), are a subset of a larger study of discourse coherence, or how speakers and listeners blend forms, meanings, and actions to make sense of what is said.

Discourse particles, or discourse markers, as Schourup (1982) calls them, can be used to 'stabilize' conversations with many meanings, avoiding a vacuum 'period' and allowing for a seamless flow of communication. In addition, while using discourse markers will not affect the grammatical meaning of a conversation, it will make it more entertaining, comprehensible, courteous, and forceful. Furthermore, the absence of a discourse marker 
does not make a statement ungrammatical or unintelligible, according to Fraser (1988). It does, however, take away a critical signal about the speaker's commitment to the relationship between the current utterance and the prior one.

With the current trend in language teaching shifting from grammatical to communicative ability, discourse markers have been the subject of a number of studies. However, there are two opposing approaches that deal with the study of DMs. DMs, according to the first method, are language expressions that connect discourse units. According to proponents of this approach, DMs are cohesive devices that contribute to the coherence of well-formed speech by encoding cohesive (semantic) linkages between discourse units. DMs, on the other hand, are viewed as pragmatic devices that aid speech interpretation and comprehension by embedding procedural information that affects the contextual information that is picked in the second approach. To put it another way, such devices store relevance relationships between schemas (thoughts) and the cognitive milieu of an individual. However, there is one thing that both methods have in common: they both aim to establish a theory of discourse comprehension, or how language is understood and interpreted.

\subsection{Statement of the Problem}

The goal of the study was to find answers to the following research questions:

1. What pragmatic functions does the discourse marker "well" perform in Philippine English spoken discourse in terms of:
a. Delaying marker
b. Repairing marker
c. Framing marker
d. Initiating marker
e. Mitigating marker?

2. Do the pragmatic functions of the discourse marker "well" in spoken Philippine English differ along the following dimensions:
a. Direct conversation
b. Broadcast discussion
c. Spontaneous commentaries
d. Broadcast news?

\section{LITERATURE REVIEW}

\subsection{Theoretical Framework}

The first hypothesis in this suggested study is based on Sperber and Wilson's (1995) relevance theory, according to which the discourse marker "well" can be interpreted as a sign that can encode constraints in the interpretation process and concurrent backdrop selection. It denotes that the background that is most readily available is not the most necessary for interpreting the impending statement (Jucker, 1993).

The second theory emphasized by this study is discourse and discourse analysis. Defining discourse in linguistics is twofold. Discourse is defined as "a specific unit of language" that is larger than a sentence, as well as "a specific focus (on language use)" (Schiffrin, 1994). This duality of the definition stems from two different approaches to linguistics and the study of language in general, or as Leech (1983) in Schiffrin (1994) puts it, "the two approaches are associated with very different views on the nature of language" (p.21). The two approaches, or paradigms, are the formalist or structuralist paradigm, and the functionalist or interactive paradigm. The former one views discourse as "sentences," the latter as "language use," and studies structure and function respectively. The functional approach assumes that language has functions outside of the linguistic system, and that these external functions influence the linguistic system's internal organization (Schiffrin, 1994). 
The formalist view, on the other hand, acknowledges language's social and cognitive purposes while claiming that these functions have no bearing on language's basic order. The functional technique is used to analyze the data in this research.

Likewise, the five major pragmatic functions which serve as the framework for the present study includes Junker (1993) and Ran (2003) five major pragmatic functions of the discourse marker "well" in conversation. For instance, (1) as a Delaying Marker, in which the speaker is not always ready to respond to another utterance, is hesitant to tell the truth, or needs more time to organize his or her speech; (2) as a Repairing Marker, in which a speaker may make mistakes and thus needs to repair, correct, or edit his or her own utterance while speaking; The speaker, on the other hand, cannot do so abruptly. He or she generally gives a signal that he or she is about to rectify his or her own statements to the addressee(s); (3) as a Framing Marker, in which the speaker may shift from one topic to another for a variety of reasons. He or she may utilize some signals to suggest that the current topic will be changed, and these signals can aid in the integration of the two independent themes into a more coherent one, preventing a sudden topic changeover; (4) DM "well" can be used as an Initiating Marker to show the speaker's acceptance or receipt of the addressee's speech and to stress the speaker's responsibility to speak; (5) as a Mitigating Marker to signal refusals, objections, and denials.

\subsection{Conceptual Framework}

The diagram of the study is presented in Figure 1. It shows the relationship between the relevance theory, discourse marker theory, and pragmatic functions of discourse marker "well" as described by Ran (2003) and Jucker (1993). Qualitative and quantitative analysis of ICE-PH along spoken discourse (direct conversation, broadcast conversation, spontaneous commentaries, and broadcast news) will shed light into the different pragmatic functions of discourse marker "well" across different forms of spoken discourse in Philippine English. As a result, the goal of this investigation is to show how the DM "well" and its pragmatic functions are utilized in spoken Filipino English.

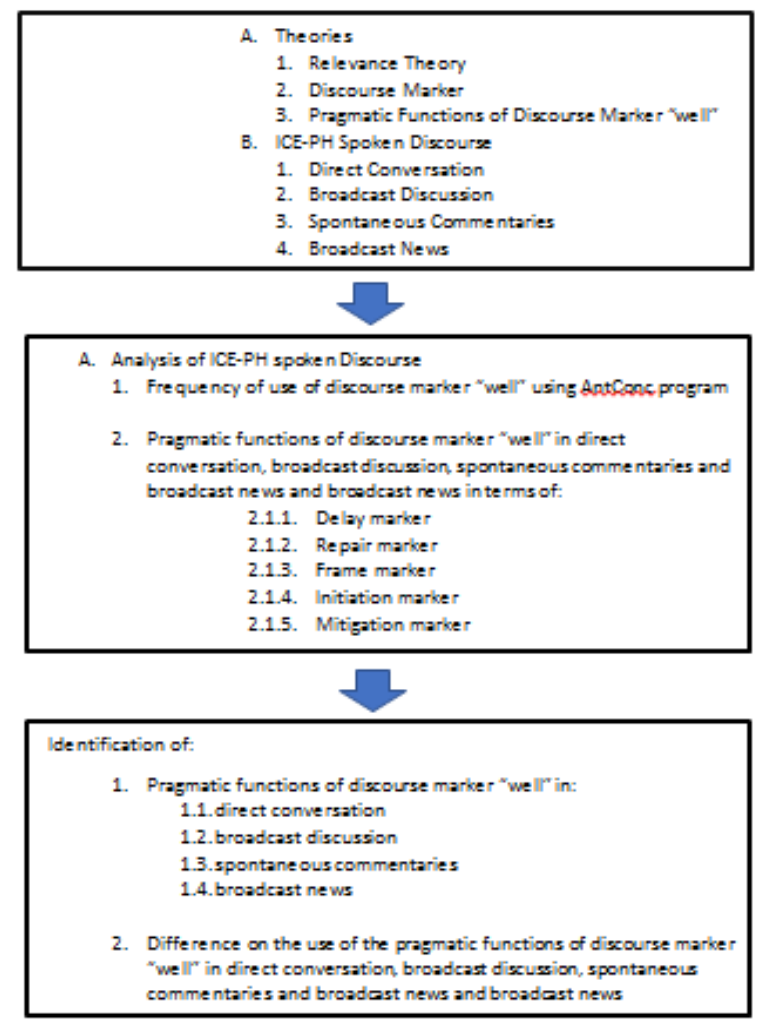




\subsection{Related Studies}

Figure 1.Paradigm of the study

While earlier research has looked into the acquisition of English morphology, syntax, and phonology by non-native English speakers, there have been few studies that have looked into the acquisition and usage of English discourse markers (DMs) by ESL students. The following are some of the studies that deal with DMs in an ESL context:

Chaudron and Richards (1986) investigated the impact of several discourse markers on foreign language students' understanding of university lectures. They divided cues into macro and micro markers, with the former referring to cues used to suggest inter-sentential links or serve as pause fillers, while the latter referring to cues used to convey the relationship between important segments or to highlight the major transition points in discourse (well and so). The study discovered that macro markers considerably aid lecture comprehension, although the study's favorable impacts on micro markers were not thoroughly examined.

Furthermore, Fung and Carter (2007) investigated the usage of discourse markers in a corpus of spoken British English and a corpus of interactive classroom speech among Hong Kong secondary students. The study's findings revealed that discourse markers are important interactional tactics for structuring and organizing speech on interpersonal, referential, structural, and cognitive levels in both groups. L2 learners employ a lot of referentially functional discourse markers like and, but, because, OK, and so, but they use a lot less of other markers like yeah, really, say, sort of, I see, you see, well, you know.

In a similar study, Akande (2009) found that discourse markers in spontaneous speech of Nigerian university graduates (NUGs) serve several socio-pragmatic purposes such as reparation, clarification, and gap filling. It was discovered that the employment of discourse markers differed by geography between the Southwest (or Southeast) and the North. Jung (2008) also looked at discourse markers in cross-cultural conversations, and found that L2 learners not only understand what these markers signify, but also have the ability to apply them in a socially useful way. Meanwhile, Tan-de Ramos (2010) did a study on discourse marker types in the body part of De La Salle University students' research papers, which may be connected back to studies of discourse marker well in the Philippine environment. It was discovered that students' preferences for specific discourse markers are determined by the type of research paper expected of them and the discipline to which they belong. She went on to say that these findings are significant in the field of language education, particularly in writing, because language teachers may pay close attention to the demands of students from other disciplines and tailor their instruction to meet those needs.

Finally, Palacio and Gustilo (2016) found that discourse particles have essential and crucial consequences in the way Filipinos, particularly the youth, express their statement, acquire knowledge of the received message, and establish speaker-receiver relationships and attitudes on Facebook in their study on the pragmatic analysis of discourse particles in Filipino computer mediated communication. Participants have also used the discourse particle well to demonstrate sarcasm and to describe something they are proud of.

Indeed, several of the research discussed above looked at the general characteristics of discourse markers, while others concentrated on a theoretical account of a specific marker and undertook an empirical investigation of discourse markers in general or a specific one. Few studies have looked at the functional distribution frequencies of the discourse marker 'well' (Li \& Xiao, 2012; Baiat, et al., 2013), and there is a need for a study in the Philippines that focuses solely on pragmatic functions of the DM "well," as the DM "well" was found to be one of the most frequently used DMs in the International Corpus of English - Philippines (ICE-PH) spoken corpus.

In this end, past research in the Philippines concentrated on written discourse such as student essays and blogs. The goal of this study is to describe the use of the discourse marker 
"well" in spoken discourse using the ICE-PHI, which is a good representation of naturally occurring discourses in the Philippines.

\section{METHODOLOGY}

The research used the Philippine component of the International Corpus of English (ICE-PH), which was searched individually for the word "well." ICE-PH comprises around one million words and is made up of 500 texts, each of which contains approximately 2,000 words. The texts were chosen from specific text categories, with the quantity of texts in each category defined. Since ICE-PH is made up of two categories, the spoken corpus and written corpus, the study only focused on the former. Also, the spoken corpus was divided into four parts, namely: dialogue: private, dialogue: public, monologue: unscripted and monologue: scripted. The following text types and its subcategories along with its corresponding code numbers are given below:

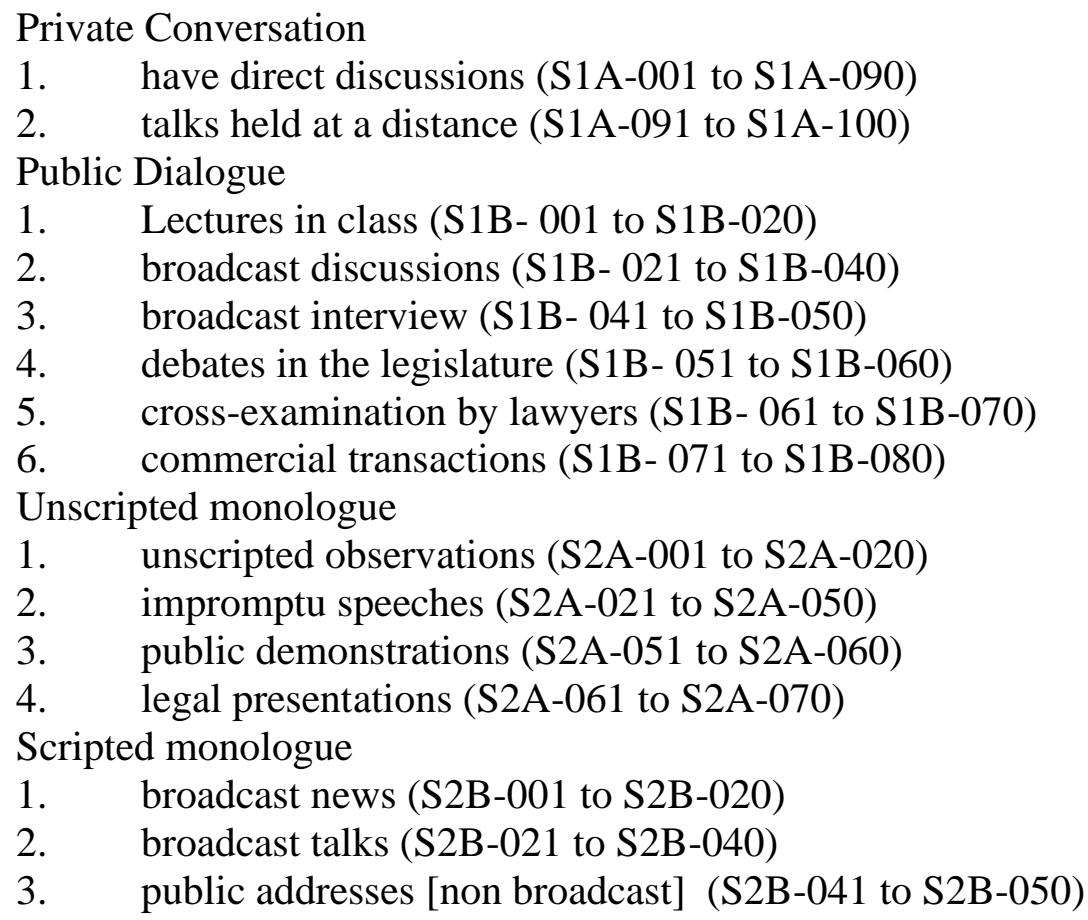

The ICE-PHI was chosen for the study due to its accessibility, size, and quantity of varied samples it contains. The above listing shows that the ICE-PHI contains a vast number of various transcriptions of spoken language, thus for the purpose of this paper, the researcher chose only four subcategories that will serve as a representative of each major categories, and these are: direct conversation for dialogue private, broadcast discussion for dialogue public, spontaneous commentaries for monologue unscripted and finally, broadcast news for monologue scripted. It should be noted as well that the entries for direct conversation range from 001-090 which is different from the sizes of the other samples considered in the study. For this reason, the researcher selected subject S1A-001 to S1A-020 of the direct conversations for the analysis. The rationale for this is to ensure that the sizes of each corpus being studied are consistent. The reason for using spoken discourse is because the DM "well" and its pragmatic functions are best observed in spoken form rather than written mode, as Leech and Svartvik (2002) pointed out.

Furthermore, the AntConc program was used to examine the general occurrence of "well" as a discourse marker, as well as its respective frequencies as a delay marker, an initiation marker, a repair marker, a frame marker, and a mitigation marker in the corpus.

Since the word "well" can have multiple meanings, the search word yielded results that needed weeding. Thus, in weeding the corpus, only those sentences in which well are 
used as a discourse marker (interjection or exclamation) were taken into consideration. Table 1 below shows how many tokens of well in the individual types of spoken discourse were found and how many examples met the above mentioned criteria:

Table 1. The distribution of well across different types of spoken discourse in ICEPHI

Discourse marker Well in different types of spoken discourse Hits in ICE-PHI

Hits in the ICE-PHI meeting the criteria

Direct Conversation $132 \quad 114$

Broadcast Discussion $166 \quad 145$

Spontaneous Commentaries $109 \quad 83$

Broadcast News $\quad 19 \quad 4$

TOTAL $\quad 426 \quad 346$

In order to answer research question number 1, the researcher employed both qualitative and quantitative methods of analysis. The items of well that fit in the criteria set (noun, adjective, adverb and verb weeded out) were individually analysed following the parameters provided by Junker's (1993) and Ran 's (2003) five main pragmatic purposes of DM "well" as stated above. Simple frequency count, percentage, and rank were used.

Lastly, to answer research question number 2, the researcher still used frequency count, percentage and rank. The raw frequency of various uses of "well" in the four spoken corpora was compared, and further discussions for each spoken discourse subtype were conducted.

\section{RESULTS AND DISCUSSION}

\section{DM “well” pragmatic functions in spoken discourse of Philippine English}

As Table 2 suggests, $46.53 \%$ of the DMs well in spoken discourse were used as an initiation marker, followed by $25.43 \%$ of the DMs which were utilized as a delay marker. Also, $14.74 \%$ of the DMs were employed as a frame marker, and $7.23 \%$ corresponds as a mitigation marker, leaving the remaining $6.07 \%$ for repair marker as a pragmatic function.

Table 2. DM well pragmatic functions in spoken discourse of Philippine English.

\begin{tabular}{cccc}
\hline Pragmatic Function & Frequency & Percentage & Rank \\
\hline Delay Marker & 88 & 25.43 & 2 \\
Repair Marker & 21 & 6.07 & 5 \\
Frame Marker & 51 & 14.74 & 3 \\
Initiation Marker & 161 & 46.53 & 1 \\
Mitigation Marker & 25 & 7.23 & 4 \\
TOTAL & 346 & 100 & \\
\hline
\end{tabular}

DM "well" is basically a response marker, according to Schiffrin (1987), which anchors its user in an engagement when an upcoming contribution is not totally coherent with earlier coherence possibilities. As can be seen in the examples, the DM well was used as an initiation marker, which appears mostly in initial position and sometimes in medial position. Consider the following examples:

(1) A: Wow that's good for you.

B: Well I'm always absent and late even though I live so near $<$ S1A-013\#172>

(2) A: I think they give you gift certificates

$\mathrm{B}$ : Well more of our complaints questions and suggestions about consumer rights we come back <S1B-035\#70>

Furthermore, Sacks et al. (1974) recognized "well" as a turn initiator, frequently launching a new speech or commencing a turn. Thus, it follows that DM well can be found in 
the initial position. Also, it was found that beginning a turn is the most commonly used function of DM well. Here are other examples where well functions as an initiator marker:

(3) A: Trish is a lot prettier than his ex-girlfriend.

B: Well I'm sure Trish would like that would like to hear that. $<$ S1A-015\#42>

(4) A: Was there not uh also uh an opportunity for PHIVOCS to determine that there could be...

B: Well it's hard to project that $<$ S1B-022\#47>

The second pragmatic function that DM "well" encodes is as a delay marker. The use of DM "well" as a delay marker can be observed in situations where the speaker is not immediately ready to respond to another utterance, or is hesitant to tell the truth to some extent, or needs more time to organize what they want to say, or is unsure about how to state what they want to say. Take for example the following excerpts taken from the corpus.

(5) A: Uh-huh who else?

B: uh well David Robinson <S1A-001\#163>

(6) A: And when you have your downs isn't that difficult having a business together?

B: No uhmm well in our case because both of us are kind of strong... $<$ S1B-026\#84>

As shown in the cases above, the DM "well" used as a delay marker is accompanied by linguistic cues such as uhm and uh to keep the floor and turn seemingly incoherent units of utterances into intelligible ones.

In other circumstances, the speaker may change or transfer the current topic of discussion to a different one for a variety of reasons, and in order to maintain coherence, the speaker may use the DM "well" to signal that he or she is changing the current topic. As a result, DM "well" serves as a frame marker, bringing two disjointed themes together into a more cohesive one to avoid a sudden topic change. This pragmatic function resembles the initiation marker, but the DM "well" used in this function occurs in medial position and is embedded in a single utterance, unlike in an initiation marker where it can be typically found in the initial position (See example 8).

...I said nobody will advise this in the Philippine Normal College and she said well I accepted because uhm she is a good student... $<$ S1A-003\#225>

Well there are other men before Joey who also had that kind of situation with many children hmmm but well it's up to them. $<$ S1A-006\#175>

A mitigation marker is the fourth pragmatic function of the DM "well." DM "well" is sometimes employed as a linguistic indicator of politeness (to save face), and so can be considered a mitigation marker, which usually appears at the start of a sentence. As the examples below show, the usage of DM "well" in this scenario usually denotes refusals, objections, and denials to a particular speech (Li \& Xiao, 2012).

(9) A: Yeah I am not saying my age just for this conversation. No thanks.

B: Well don't worry you'll not be forced to. $<$ S1A-002\#297>

(10) A: Uh so it's like you're paying this guy he's he's your employee

B: Well our employee in terms of cleaning but we just give a minimal amount...<S1A- 006\#8>

Finally, DM "well" can be seen as a repair marker in some circumstances where speakers need to mend, rectify, or alter their statement throughout a dialogue. The speaker normally provides the addressee(s) some signals that he or she is going to correct his or her words in these cases. These clues show the speakers' attempt to bring seemingly semantically 
disparate units of speech together into a coherent whole. One of these signals, according to Li and Xiao (2012), is the discourse marker "well," which functions as a repair marker in the following example:

(11) Something like uh uh eighteen well seventeen percent uh other areas...<S2A-001\#36>

(12) Countryside development one area in the past administration which was well not with the Aquino administration I guess... $<$ S2A-001\#90>

\section{Pragmatic roles of discourse marker well in different spoken discourse of Philippine English}

The usage of different pragmatic functions differs across different spoken discourses in Philippine English, according to the examination of the pragmatic functions of DM "well" in different spoken discourses. Table 3 shows how many examples of the individual tokens of well were found in different spoken discourse and how many of these examples of well were considered as a discourse marker. The distribution of discourse marker well across different spoken discourse is presented

According to the table below, the DM "well" is widely employed as a discourse marker in various spoken forms of Philippine English. DM "well" was used as a discourse marker 346 times out of 426 tokens, accounting for 81.22 percent. The DM "well" was also widely used in broadcast debate ( 87.34 percent), followed by direct conversation (86.36 percent), spontaneous commentary (76.15 percent), and broadcast news (76.15 percent) (21.05 percent). As a result, how DM "well" is used as a discourse marker changes depending on the sort of spoken discourse.

Table 3.Distribution of discourse marker well across different spoken discourse

\begin{tabular}{ccccc}
\hline Spoken Discourse & No. of Hits & Well as DM & Percentage & Rank \\
\hline Direct Conversation & 132 & 114 & 86.36 & 2 \\
Spontaneous Commentaries & 109 & 83 & 76.15 & 3 \\
Broadcast Discussion & 166 & 145 & 87.34 & 1 \\
Broadcast News & 19 & 4 & 21.05 & 4 \\
Total & $\mathbf{4 2 6}$ & $\mathbf{3 4 6}$ & $\mathbf{8 1 . 2 2}$ & \\
\hline
\end{tabular}

In summary, Table 4 shows the general usage variations of the different pragmatic purposes of DM "well" across the four spoken discourse types analysed. As the table indicates, broadcast discussion, direct conversation, spontaneous commentaries and broadcast news differ in the use of "well" as a discourse marker. Likewise, the pragmatic functions of DM "well" vary according to speech category.

Table 4. Functions of well as a DM in all the four spoken discourse categories analyzed

\begin{tabular}{cccccc}
\hline $\begin{array}{c}\text { Pragmatic } \\
\text { Function }\end{array}$ & $\begin{array}{c}\text { Broadcast } \\
\text { Discussion }\end{array}$ & $\begin{array}{c}\text { Direct } \\
\text { Conversation }\end{array}$ & $\begin{array}{c}\text { Spontaneous } \\
\text { Commentaries }\end{array}$ & $\begin{array}{c}\text { Broadcast } \\
\text { News }\end{array}$ & TOTAL \\
\hline $\begin{array}{c}\text { Delay } \\
\text { Marker }\end{array}$ & 46 & 26 & 16 & 0 & 88 \\
$\begin{array}{c}\text { Repair } \\
\text { Marker }\end{array}$ & 8 & 8 & 5 & 0 & 21 \\
$\begin{array}{c}\text { Frame } \\
\text { Marker }\end{array}$ & 13 & 15 & 19 & 4 & 51 \\
$\begin{array}{c}\text { Initiation } \\
\text { Marker }\end{array}$ & 73 & 48 & 40 & 0 & 161 \\
$\begin{array}{c}\text { Mitigation } \\
\text { Marker }\end{array}$ & 5 & 17 & 3 & 0 & 25 \\
\hline TOTAL & 145 & 114 & 83 & 4 & 346 \\
\hline
\end{tabular}




\section{Discussions}

The results of the present study revealed qualitative and quantitative similarities and differences between the pragmatic functions of discourse marker well and type of spoken discourse. The use of DM well shows that ESL Filipino speakers use this in ways parallel to native speakers or in a native like manner. The overall findings about the use of DM "well" are similar to the outcomes of previous studies (Schiffrin, 1987; Muller, 2005; Fuller, 2003; Buysse, 2012; and Jucker \& Smith, 1998). Furthermore, the frequency of usage of DM "well" in Philippine English spoken discourse is consistent with Hellerman and Vergun's (2007) study of bilingual adult English learners, which found that students who use more discourse markers are more acculturated to the United States.

In terms of the pragmatic roles of the discourse marker "well" in Philippine English spoken discourse, the study found that Filipino English speakers tended to employ it as an initiation marker and as a delay marker. These findings are comparable to those of Li and Xiao (2012), who found that native and non-native English speakers both choose to utilize the discourse marker as a delay and initiation marker. For both L2 and L1 adult users, the two features account for at least 65 percent of all usages.

Similarly, DM's "well" effectiveness as an initiating marker backs up Schiffrin's (1987) statements that DM "well" effectively marks speech acts, offers cohesive linkages between clauses and utterances, and regulates the transition between two themes and topics and subtopics. Also, the work of Halliday and Hasan (1992), which pays special emphasis to the six items: now, of course, well, anyway, undoubtedly, and after all, can be tracked as an initiation marker. The study discovered that DM "well" occurs at the start of a dialogue response. It might be seen as either acknowledgment of the inquiry and preparation to respond or a pause. This observation backs up the findings of the current investigation. The pragmatic function of DM "well" as a delay marker, on the other hand, is frequently used in three ways in this study: (1) when the speaker is not immediately ready to respond to another utterance; (2) when the speaker is reluctant to tell the truth; and (3) when the speaker needs more time to organize his or her talk. These observations are similar to the Ran (2003) and Jucker (1991) findings. Another key finding of this study is that distinct pragmatic functions of DM "well" are used differently in different types of spoken discourse, such as broadcast discussion, direct dialogue, spontaneous remarks, and broadcast news.

In the four speech categories under investigation, the most common functions of "well" as a DM are those of a new turn opener, initiating function, and a delaying function. It follows that the use of "well" in these two functions is consistent with the type of the speech category. It has also been proved that some functions of "well" as a DM are more likely to appear in certain types of spoken discourse categories than in others, for example, "well" as a marker of frame is more likely to be used in monologue: scripted and monologue: unscripted, while "well" as a marker of mitigation tend to be used more frequently in direct conversations than in other spoken discourse types. Finally, "well" as a marker of repair is observed as one of the most underutilized pragmatic functions of DM "well", both in dialogue and monologue. These findings are related to study made by Fuller (2003) wherein presentation and reception markers were examined in two speech context: semi-formal interviews and casual conversation. The study revealed that contextual characteristics such as the roles of the speakers and the relationship between interlocutors could shape the distribution patterns of certain discourse markers. Fuller (2003) also added that the marker well occurred more frequently in casual conversation, which is also the case in this current study.

Finally, given the restricted use of discourse marker "well" in broadcast news, discourse markers are considered to be predominantly an oral rather than written discourse element. As claimed by Jucker (2002) in his investigation of discourse markers in EModE that the frequency of discourse markers is a direct indicator of the amount of (representations 
of) spoken language that is expected to appear in any certain genre. As a result, discourse markers were found in high numbers in EModE text types that are related to spoken language. The depiction of spoken language is filtered and standardized since broadcast news texts were originally created to be spoken. As Murillo and Yeh (2021) pointed out, people must realize that culture and communication are inextricably linked, and that culture is built on symbols that allow us to share and comprehend the meanings of one's actions.

\section{CONCLUSION}

The following conclusions are formed in light of the study's findings: First, the pragmatic functions of the discourse marker "well" found in spoken Philippine English encompass a wide range of functions. Delay marker, repair marker, frame marker, initiation marker, and mitigation marker are some of the practical functions of DM "well." Also, the initiation marker was found to be the most regularly used pragmatic function by speakers of Philippine English among these five pragmatic functions of "well." This is followed by pragmatic functions: delayed marker, frame marker, and repair marker. Second, the pragmatic roles of DM "well" in Philippine English spoken discourse differ along direct conversation, broadcast discussion, spontaneous commentaries and broadcast news. In broadcast discussion, initiation marker has been found to be frequently used pragmatic function of "well", followed by delay marker, frame marker, repair marker and mitigation marker. Also, in direct conversation, the pragmatic function 'initiation marker' was frequently used followed by 'delay marker', 'mitigation marker', 'frame marker', and 'repair marker'. Further, in spontaneous news, initiation marker ranked first, followed by 'frame marker', 'delay marker', 'repair marker' and 'mitigation marker'. Finally, in broadcast news, the pragmatic function 'an initiation marker' of the discourse marker "well" was solely used.

The practical usage of the study can be employed for pedagogical objectives based on the findings of this investigation. Discourse markers like "well" are overused in Philippine English, as seen by the findings. It shows that Filipinos tend to employ such linguistic signal in speaking the English language, either in casual conversation or in a more formal type of spoken discourse like broadcast discussions. It should be emphasized, however, that this marker is commonly utilized in face-to-face spoken conversation, making it useful in conceiving a more natural dialogue modeling. For example, textbook compilers who, as Leech (2001) argues, tend to present English learners in the Philippines with ideal speaker utterances that rarely occur in everyday speech must present the language learners with natural discussions.

Next, due to the high frequency of such short words as discourse markers in spoken conversation, language teachers must improve students' awareness of these DMs during the teaching process. Raising students' awareness requires clearly explaining these discourse markers, because, as Ellis (2002) points out, explicit education can speed up language acquisition and explicit instruction is more effective than implicit training. Furthermore, a study of the pragmatic functions of the discourse marker "well" in use, as well as the manner in which it is used, which varies from context to context, could help language teachers encourage their students to think more critically about discourse markers in general, and the discourse marker "well" in particular. This type of analysis will also serve as a tool for developing awareness among students and teachers, so that the usage of discourse markers is not overlooked while writing and, more importantly, when speaking.

Finally, with today's massive English contents, second language learners should focus more on how the varied pragmatic roles of the discourse marker can be successfully used, organized, and structured. This will help them in the future when they are faced with similar communicative challenges. As a result, their critical awareness has increased, as has their desire to diversify their linguistic choices. 


\section{REFERENCES}

Andersen, E., Brizuela, M., Dupuy, B.C., \& Gonnerman, L. (1999). Cross-linguistic evidence for the early acquisition of discourse markers as register variables. Journal of Pragmatics, 31, 1339-1351.

Aijmer, K., \& Simon-Vandenbergen, A. (2003). The discourse particle well and its equivalents in Swedish and Dutch. Linguistics, 41 (6), 1123-1161. DOI: 10.1515/ling.2003.036.

Biber, D., Johansson, S., Geoffrey, L., Conrad, S., \& Finegan, E. (1999). Longman grammar of spoken and written English. Pearson Education Limited.

Blakemore, D. (1987). Semantic constraints on relevance. Blackwell.

Blakemore, D. (1992). Understanding utterances. Blackwell.

Blakemore, D. (2002). Relevance and linguistic meaning: The semantics and pragmatics of discourse markers. Cambridge University Press.

Brown, G., \& Yule, G. (1983). Discourse analysis. Cambridge University Press.

Coulmas, F. (1989). The writing systems of the world. Blackwell.

Coulmas, F. (ed). (1999). Functions of writing. In: The Blackwell Encyclopedia of Writing Systems. doi: 10.1111/b.9780631214816.1999.x

De Ramos-Tan, J. (2010). A comparative study of the discourse marker types in the body section of the research papers of DLSU students. TESOL Journal, 2, 62-73.

Fraser, B. (1999). What are discourse markers? Journal of Pragmatics, 31, 931-952. http://dx.doi.org/10.1016/S0378-2166(98)00101-5

Halliday, M. A. K., \& Hasan, R. (1989). Language, context, and text: Aspects of language in a social-semiotic perspective. Oxford University Press.

He, A., \& Xu, M. (2003). Chinese EFL learners' use of small words. Foreign Language Teaching and Research, 35, 446-452.

Jucker, A. H. (1993). The discourse marker well: A relevant theoretical account. Journal of Pragmatics, 19, 435-452. http://dx.doi.org/10.1016/0378-2166(93)90004-9

Leech, G., Deuchar, M., \& Hoogenraad, R. (1982). English grammar for today: A new introduction. Macmillan Press.

Leech, G., \& Svartvik, J. (2002). A communicative grammar of English (3rd edition). Pearson Education.

Lenk, U. (1998). Marking discourse coherence: Functions of discourse markers in spoken English. Gunter Narr.

Levinson, S. C. (1983). Pragmatics. Cambridge University Press.

Li, M., \& Chen, X. (2007). Chinese English majors' grammatical and pragmatic awareness as well as their respective competence: An empirical study. Foreign Languages in China, 6, 35-41.

Li, M. \& Xiao, Y. (2012). A comparative study on the use of the discourse marker "well" by Chinese learners and native English speakers. International Journal of English Linguistics,2 (5), 65-71. 
McEnery, T.\& Wilson, A. (1996). Corpus linguistics. Edinburgh University Press.

Murillo, M. \& Yeh, Aiden. (2021). The failed rhetoric: Presupposition analysis on Duterte's 5 th state of the nation address. International Journal of Language and Literary Studies, $3(2)$.

Povolná, R. (2010). Interactive discourse markers in spoken English. Masarykova univerzita.

Palacio, M.A. \& Gustilo, L.E. (2016). A pragmatic study of discourse particles in Filipino computer mediated communication. Gema online Journal of Language Studies 16(3):1-19. DOI: 10.17576/gema-2016-1603-01

Quirk, R. et al. (1972). A grammar of contemporary English. Longman.

Ran, Y. (2003). The pragmatic functions of the discourse marker "well”. Foreign Languages, $151,58-64$.

Redeker, G. (1991). Review article: linguistic markers of discourse structure. Linguistics, 29, 1139-1172.

Scarcella, R. (2003). Academic English: a conceptual framework. Irvine: University of California Linguistic Minority Research Institute. Retrieved from http://esolonline.tki.org.nz/content/download/15850/110036/file/Academic+English+ A+Conceptual+Framework.pdf

Schiffrin, D. (1994). Approaches to discourse. Blackwell Publishers Ltd.

Schiffrin, D. (1987). Discourse markers. Cambridge University Press.

Sperber, D., \& Wilson, D. (1995). Relevance: Communication and cognition. Blackwell.

Sprott, R. (1992). Children's use of discourse markers in disputes: Form-function relations and discourse in child language. Discourse Processes, 15, 423-439. http://dx.doi.org/10.1080/01638539209544821

Stenström, A. (1994). An introduction to spoken interaction. Harlow: Longman Group UK Limited.

Svartvik, J. (1980). Well in conversation. In: S. Greenbaum, G. N. Leech \& J. Svartvik, Studies in English Linguistics for Randolph Quirk.Longman. 167-177.

Svartvik, J., \& Leech, G. (2006). English: One tongue, many voices. Palgrave Macmillan.

Trillo, J. S. (2002). The pragmatic fossilization of discourse markers in non-native speakers of English. Journal of Pragmatics, 34, 769-784. http://dx.doi.org/10.1016/S03782166(02)00022-X

Uribe, D. (2008). Characteristics of academic English in the ESL classroom. The Internet TESL Journal, 14 (3).

Well. 2014. In Merriam Webster Dictionary. Retrieved March 15, 2017, from https://www.merriam-webster.com/dictionary/dictionary

Well. (1995).The Cambridge International Dictionary of English (p. 1651-1652).Cambridge University Press

Yule, G. (1996). Pragmatics. Oxford University Press.

Zarei, F. (2013). Discourse markers in English. International Research Journal of Applied and Basic Sciences, 4 (1), 107-117. 


\section{AUTHOR'S BIO}

Dr. Jimmylen Zuñiga-Tonio is an Assistant Professor at Catanduanes State University (CatSU) and the Officer-In-Charge of the Research and Development Services of CatSU. She received her PhD in Applied Linguistics from De La Salle University Manila and MA in English as a Second Language from Benguet State University. 